\title{
Communication in palliative care: talking about the end of life, before the end of life
}

\author{
Lisa Jane Brighton, Katherine Bristowe
}

King's College London, Cicely Saunders Institute, Department of Palliative Care, Policy, \& Rehabilitation, London, UK

\section{Correspondence to} Lisa Jane Brighton, King's College London, Cicely Saunders Institute, Department of Palliative Care, Policy, \& Rehabilitation, Bessemer Road, London SE5 9PJ, UK; lisa.brighton@kcl.ac.uk

Received 11 June 2015 Revised 8 April 2016 Accepted 17 April 2016 Published Online First 6 May 2016
CrossMark

To cite: Brighton $\mathrm{U}$ Bristowe K. Postgrad Med J 2016;92:466-470.

\section{ABSTRACT}

Increasing evidence demonstrates the benefits of early end-of-life care discussions with patients with lifethreatening illness and their families. However, these conversations often do not occur. This review explores some of the many barriers faced by clinicians in relation to end-of-life care discussions, including prognostic uncertainty, fear of causing distress, navigating patient readiness and feeling unprepared for these

conversations. The value of core clinical communication skills, potential strategies for improvement and areas for future research are also discussed. It is essential that clinicians offer patients facing life-threatening illness, and those close to them, the opportunity to discuss end-of-life issues in line with their information and decision-making preferences. With a growing and ageing global population, supporting both generalist and specialist providers of palliative care in this task is key. With careful preparation, fears of undertaking these discussions should not be a barrier to initiating them.

\section{INTRODUCTION}

Palliative care aims to improve the quality of life of patients with life-threatening illness and their families. ${ }^{1}$ Although palliative care is applicable and valuable throughout the disease trajectory, ${ }^{2-5}$ some of the most challenging discussions in palliative care are regarding end-of-life issues. This can include talking about prognosis, preferences and priorities (eg, life-prolonging and/or palliative treatments, place of care, place of death), as well as hopes and fears regarding dying and death-a process often formally referred to as anticipatory or advance care planning (ACP). In the context of a growing and ageing global population, the demands for palliative care services cannot be met by specialists alone. ${ }^{6-8}$ Therefore, the responsibility of communicating about end-of-life care with individuals with life-threatening illness, and those close to them, will increasingly fall to generalist, as well as specialist, providers of palliative care.

The importance of communication in healthcare has long been recognised within medical education as a foundation of good care, ${ }^{9}{ }^{10}$ and reports continue to highlight the need for open and honest discussions with patients, and those close to them, at critical times. ${ }^{11} 12$ Despite this, 60\%-90\% of patients with life-threatening illness report never having discussed end-of-life care issues with their clinician. ${ }^{13-15}$ This review aims to summarise the evidence regarding the importance of timely end-of-life care discussions, explore barriers faced by clinicians and highlight key findings and recommendations for practice.

\section{WHY ARE END-OF-LIFE CARE DISCUSSIONS SO IMPORTANT? \\ The benefits}

There is strong evidence of the benefits of end-of-life care communication with patients with lifethreatening illness and their families. Discussing a greater number of end-of-life care topics increases the likelihood of concordance between patientreported goals of care and the goals documented within their medical records, and increases patient satisfaction with care. ${ }^{16}$ Indeed, in a recent US study of patients with chronic obstructive pulmonary disease (COPD), those who reported having end-of-life care discussions were twice as likely to rate the quality of their care as the best imaginable, ${ }^{13}$ Furthermore, end-of-life care discussions also influence subsequent treatment decisions: a recent prospective study of over 1000 US patients with cancer found that end-of-life care discussions prior to the last 30 days of life were significantly associated with fewer aggressive medical interventions. ${ }^{17}$ Although aggressive medical interventions may be appropriate for, and preferred by, some individuals, patients' quality of life and relatives' bereavement adjustment are reported as significantly better when patients receive fewer aggressive medical treatments towards the end of life. ${ }^{14}$ Findings across each of these studies are consistent with a recent systematic review of the impact of ACP on end-of-life care, which, across over 100 studies, found evidence of a positive impact in the form of reduced hospitalisations, increased use of hospice and palliative care services, decreased use of life-sustaining treatments and better compliance with patients' wishes. ${ }^{18}$

\section{Sooner, rather than later}

In addition to the benefits of having discussions about end-of-life care issues, research has also demonstrated the importance of initiating such conversations sooner, rather than later. In a recent Canadian study ${ }^{19}$ physicians, residents and nurses reported that one of the top five barriers to 'goals of care discussions' was patients' lack of capacity. In line with this report, a recent review of the medical records of outpatients with cancer in the USA demonstrated that while $79 \%$ of patients were deemed to have capacity when admitted to hospital, $40 \%$ of these individuals lost capacity before an end-of-life care discussion could take place. ${ }^{20}$ Patients who lost capacity, and therefore had surrogate decision-makers, were significantly more likely to receive more aggressive life-sustaining treatments than those who took part in their own end-of-life care discussions. The impact of early discussions can also extend to those close to patients prior to death, and into bereavement. In a recent US 
qualitative study, family members stated that timely end-of-life care discussions enabled them to make the most of the time they had with the patient, and make use of hospice and palliative care services sooner. ${ }^{21}$ In addition, having such conversations before the patient becomes too unwell can be crucial in allowing relatives to prepare for death while also maintaining hope. ${ }^{22}$ It has been recommended that critical events such as diagnosis, perceptions of a change in condition (eg, patient with COPD experiencing more frequent exacerbations), presentation of unrealistic expectations (eg, patient with heart failure seeing treatments as curative), discussions about treatment complications or decisions (eg, poor response to anticancer treatment) or referral to palliative care may all act as prompts to start end-of-life discussions. ${ }^{23}$ This is not a prescriptive or exhaustive list, but may highlight useful prompts for healthcare practitioners to provide opportunities for discussion.

\section{WHY DO CLINICIANS FIND THESE DISCUSSIONS SO DIFFICULT?}

Despite strong arguments for opening and expediting end-of-life care discussions, for many people living with a life-threatening illness, these conversations still do not occur: fewer than $40 \%$ of patients with cancer, ${ }^{14} 15 \%$ of patients with $\mathrm{COPD}^{13}$ and $10 \%$ of patients with chronic kidney disease ${ }^{15}$ report having discussions about end-of-life care issues with their clinician. Often patients and relatives will wait for the topic to be raised by their clinician, ${ }^{24}$ while clinicians rely on patients and relatives to start the conversation-aptly captured in the paper by Almack and colleagues, titled 'After You'. ${ }^{25}{ }^{26}$ Consequently, this can result in a perpetual cycle of non-discussion. This cycle is fuelled by multiple barriers, including (but not limited to) prognostic uncertainty, fear of the impact on patients, navigating patient readiness and feeling inadequately trained for, or unaccustomed to, such discussions. ${ }^{19} 25-30$

\section{Prognostic uncertainty}

Uncertainty regarding disease trajectory and prognosis has frequently been cited by clinicians as a cause for avoiding end-of-life care discussions, particularly for non-malignant lifethreatening illnesses. ${ }^{26}$ As a result, these patient groups are significantly less likely to experience ACP discussions. ${ }^{31}$ This was recently explored in a study in Belgium, ${ }^{27}$ where general practitioners described their difficulty with recognising the 'terminal stage' or a 'key moment' in the illness trajectory for people with dementia and heart failure, in order to prompt ACP discussions. Similarly, in a recent study of Dutch patients with organ failure, approximately $70 \%$ had not experienced complete discussions about end-of-life care. ${ }^{32}$ While uncertainty regarding disease trajectory and prognosis may obscure the 'best time' for an end-of-life discussion, it is this very uncertainty which makes provision of opportunities for early discussion so important. Patients and relatives may not choose to take up these opportunities: patients with organ failure, for example, can be particularly reluctant to contemplate death and dying. ${ }^{33}$ However, providing opportunities for discussion, for example, when an illness-related change occurs (see above), is crucial. Although discussions were infrequent in Houben's study of patients with organ failure, ${ }^{32}$ when they did occur they were rated well for quality (scoring 6-8 out of 10 ), suggesting anticipation regarding the discussion should not be a reason to avoid one.

\section{Fear of causing distress}

Another perceived barrier that inhibits discussion initiation by healthcare providers is concern about the potential impact of end-of-life care discussions on patients and those close to them. Research has shown that many clinicians continue to avoid these discussions due to a fear of destroying hope or causing harm. ${ }^{25} 26{ }^{30}$ Indeed, maintaining hope has been identified as extremely important to patients and relatives. ${ }^{34}$ However, hope is not necessarily incompatible with knowledge of lifethreatening disease or prognosis, and can mean more than simply survival. ${ }^{35}$ A recent review of the literature found that patients can maintain hope while also acknowledging their terminal prognoses, whether they continue to hope: for a cure; to live longer than expected; to enjoy a good quality of life; to achieve personal goals or to have a peaceful death. ${ }^{34}$ Furthermore, a recent study of Japanese family members found that $73 \%$ were able to both maintain hope and prepare for the patient's death. ${ }^{22}$ With regard to causing harm, evidence suggests that end-of-life care discussions are not associated with poorer psychological patient outcomes, ${ }^{14}$ and that the majority of terminally ill patients and their relatives do not find talking about death, dying and bereavement stressful. ${ }^{36}$

\section{Navigating patient readiness}

While offering these conversations is unlikely to cause harm, this is not to say that all patients will be ready or willing to take part. Although the majority of patients do want to receive information about end-of-life care, the timing of this information is critical—when they are ready, and not before. ${ }^{35} 3738$ As a result, many patients, at some time, will be reluctant to talk about end-of-life care, and it may be particularly difficult for healthcare providers to assess the appropriate time. However, patients have acknowledged the difficulty clinicians may face here, and suggest that asking about readiness directly may be an effective strategy. ${ }^{35}$ Similarly, it can be advisable to enquire about the preferences of patients and relatives regarding level of information and involvement in decisions. Professionals are very poor at estimating these preferences; ${ }^{39}{ }^{40}$ however, exploring them with patients can increase satisfaction, improve confidence among clinicians and is not associated with heightened distress for the patients. ${ }^{41}$ Preferences for the type and amount of information, as well as involvement in decisions, should therefore form part of early interactions with patients and families. This is not a case for simply checking the 'end-of-life care conversation' box; it is about providing and signposting clear opportunities for patients and relatives to discuss their preferences and concerns, including chances for them to be revisited and changed. ${ }^{38}$ Presenting these opportunities and subsequent decisions as flexible and amenable to change is valued by patients with lifethreatening illness and their relatives. ${ }^{42}$ So long as opportunities are provided, recipients of care can guide discussions according to their readiness and preferences.

\section{Feeling unprepared}

Despite the apparent benefits of providing opportunities for these conversations, many professionals continue to feel unprepared for, or unaccustomed to, discussions about end-of-life care, and unsure about the linguistic and stylistic features preferred by patients and relatives. ${ }^{26}{ }^{43}{ }^{44}$ Indeed, the literature exploring these areas can appear contradictory and difficult to follow. Research suggests that information must be honest, while maintaining hope, ${ }^{21} 343845$ but not so much hope that it gives unrealistic expectations. ${ }^{21}{ }^{34}$ Information should be delivered in a way that shows empathy, but not pity, ${ }^{45}$ in a manner that is candid but not blunt. ${ }^{21} 35$ 46 With regard to terminology, research has suggested that explicit phrasing can lead to distress for some family members, while for others more figurative or 
indirect phrasing can lead to miscommunication. ${ }^{47}$ While these are important considerations to be cognisant of in preparing for end-of-life care discussions, we argue that of equal importance are the core, non-specialist, communication qualities that continue to be cited by patients and relatives as crucial to achieving positive communication experiences. Overwhelmingly, and unsurprisingly, patients desire to be treated as individuals, according to their preferences, ${ }^{35} 3846$ by clinicians that are able to show compassion. ${ }^{21} 46$ They want to be listened to, ${ }^{42}$ build relationships with their clinicians ${ }^{38}$ and receive holistic care ${ }^{34} 35$ in an appropriate environment with opportunities for privacy. ${ }^{35}$ These undoubtedly reflect the core competencies of clinical communication across all disciplines (medicine, nursing and allied health) rather than specialist skills specific to palliative care.

\section{WHAT CAN WE DO TO IMPROVE END-OF-LIFE CARE COMMUNICATION? \\ Training}

Due to the varied nature of perceived barriers, there is unlikely to be a 'one-size-fits-all' solution to helping clinicians open, and facilitate, conversations about end-of-life care topics. Communication skills guidelines and strategies for structuring these conversations may be one source of support, with examples including the Australian PREPARED guidelines ${ }^{23}$ and the British SAGE \& THYME model. ${ }^{48} 49$ Both are formed of evidence-based components, which, when used as a whole, have been found to improve clinicians' confidence with end-of-life care conversations. ${ }^{48} 50$ If the concern is more regarding knowledge of palliative and end-of-life care, rather than confidence in communication skills, more general education programmes have again been successful in improving clinicians' knowledge of this field. ${ }^{51-53}$

\section{Normalising: embedding end-of-life discussion into your practice}

Training and education, of course, is not the answer to all concerns about end-of-life care communication. It has been suggested that normalising end-of-life discussions could also help encourage such conversations. ${ }^{54} 55$ One novel intervention by Allen $e t a l^{56}$ combined education and training of US internal medicine residents with alterations in clinic workflow. This included medical assistants asking all patients aged over 65 about their ACPs, and preferences for discussing them, prior to appointments, providing them with written materials and alerting the physician if a patient opted to have an ACP discussion. This increased the confidence of residents undertaking these discussions, and, of those patients who did not have an existing advance care plan; $74 \%$ opted to open a discussion that day or at a follow-up appointment. Similarly, a randomised controlled study implementing a question prompt list for consecutive patients with advanced cancer increased discussion of end-of-life issues. ${ }^{57}$ These successes are in line with the suggestion of Walczak et $a l^{58}$ that multifaceted interventions may be more effective than training alone. Such efforts to normalise end-of-life discussions by embedding them within routine practice, in combination with training and support for clinicians, may help them occur sooner and more frequently.

\section{Further research}

As in the study of Allen et $a l^{56}$ above, there is a growing body of research demonstrating the success of interventions in improving clinicians' knowledge ${ }^{59} 60$ and confidence, ${ }^{60-62}$ as well as in modifying their behaviours. ${ }^{63-65}$ However, with the evidence that end-of-life care discussions are positively associated with patient satisfaction and quality of life, and relatives' bereavement adjustment, ${ }^{13} 14^{16-18}$ it also seems reasonable to expect training interventions to influence these outcomes. Yet, despite these observed relationships, there are far fewer studies demonstrating the impact of communication-focused interventions on patients' and relatives' experiences and outcomes. ${ }^{66}$ One commonly cited explanation for this is inappropriate measurement tools that lack sensitivity to change. ${ }^{67} 68$ This is problematic, as without confidence in the measures used to assess intervention effectiveness, including responsiveness to change, ${ }^{69}$ we cannot discern whether lack of effect is associated with inadequate training or inappropriate outcomes. A second explanation frequently encountered for a lack of change is ceiling effects-where high baseline scores make improvements difficult to obtain. Ceiling effects have been found in a number of interventions, including some aiming to improve patient perceptions of clinicians' empathy and communication skills, ${ }^{68}$ and ratings of therapeutic alliance ${ }^{65}$ and satisfaction. ${ }^{61} 70$ These high baseline scores raise questions as to whether intervention studies are targeting the most appropriate settings, or recruiting healthcare providers and/or patients in ways that introduce bias (eg, including those more willing to talk about end-of-life care at baseline). This would compromise our ability to assess an intervention's effectiveness. In future, more in-depth exploration of what makes 'good' end-of-life care communication, using techniques such as discourse analysis ${ }^{71} 7^{2}$ or cognitive interviewing, ${ }^{42} 73$ would be recommended to refine choice and design of outcomes. In addition, targeting interventions at clinicians or settings most in need of support may make subsequent findings more meaningful.

\section{SUMMARY}

Communication about end-of-life care issues, in line with patients' and relatives' readiness and preferences, is essential. This task increasingly will become the responsibility of generalists as well as specialist palliative care providers, and therefore supporting clinicians with this important responsibility should be a priority for practitioners, researchers and policy makers. Although there are potential barriers to opening end-of-life care discussions, it is important to recognise that many of the qualities most valued by patients and relatives are the core, nonspecialist communication skills relevant in all fields of medicine - sensitivity and empathy, within holistic, individualised care. It is therefore important not to let the specific sensitivities of palliative care discussions, as highlighted in the literature, deter clinicians from providing these all important opportunities.

\section{Main messages}

- Despite evidence supporting benefits of timely communication about end-of-life care, for many patients, these discussions do not occur.

- Clinicians face multiple barriers to these discussions, including prognostic uncertainty, fearing a negative psychological impact, navigating patient readiness and feeling inadequately trained.

- However, clinicians have the responsibility (and the core skills required) to offer opportunities for discussion throughout the trajectory of life-threatening illness, in order to empower patients and improve the care experience. 
Sources of support have been developed, and work within this field is ongoing. However, a better understanding of how we define and measure good communication in end-of-life care is essential for future progress.

\section{Current research questions}

- How can we best support clinicians to offer opportunities for end-of-life care discussions?

- Why do interventions show such variable impact on patient and family reported outcomes?

- How do we measure 'good' communication in this context?

\section{Key references}

- Andreassen P, Neergaard MA, Brogaard T, et al. Talking about sensitive topics during the advance care planning discussion: a peek into the black box. Palliat Support Care 2015;13:1669-76.

- Brinkman-Stoppelenburg A, Rietjens JA, van der Heide $A$. The effects of advance care planning on end-of-life care: a systematic review. Palliat Med 2014;28:1000-25.

- Murray CD, McDonald C, Atkin H. The communication experiences of patients with palliative care needs: a systematic review and meta-synthesis of qualitative findings. Palliat Support Care 2015;13:369-83.

- You JJ, Downar J, Fowler RA, et al. Barriers to goals of care discussions with seriously ill hospitalized patients and their families: a multicenter survey of clinicians. JAMA Intern Med 2015;175:549-56.

- Zaros MC, Curtis JR, Silveira MJ, et al. Opportunity lost: end-of-life discussions in cancer patients who die in the hospital. J Hosp Med 2013;8:334-40.

\section{Self assessment questions}

Please answer true (T) or false (F) to the below.

1. In one study, of patients entering hospital with capacity, over one-third lost capacity before an end-of-life care discussions occurred.

2. Patients with non-malignant conditions are more likely to report having discussions about end-of-life care.

3. Evidence demonstrates significant psychological harm caused by end-of-life care conversations.

4. Patients with life-threatening illness can simultaneously maintain hope and acknowledge their terminal prognosis.

5. Many of the communication skills valued by patients and relatives in end-of-life care discussions are non-specialist skills.

Twitter Follow Lisa Brighton at @Lisa_Brighton, and Katherine Bristowe at @CSI_ Linguist

Contributors $L J B$ and $K B$ wrote the manuscript in its entirety. Both authors were involved in appraising and revising the manuscript critically for important intellectual content, and gave final approval for the version to be published.

Competing interests None declared.

Provenance and peer review Commissioned; externally peer reviewed.

\section{REFERENCES}

1 World Health Organization. WHO Definition of Palliative Care. 2015. Retrieved April 2015. http://wwwwhoint/cancer/palliative/definition/en/

2 World Health Organization. WHO Definition of Palliative Care. 2015. Retrieved February 2016. http://wwwwhoint/cancer/palliative/definition/en/

3 Temel JS, Greer JA, Muzikansky A, et al. Early palliative care for patients with metastatic non-small-cell lung cancer. N Engl J Med 2010;363:733-42.

4 Brumley R, Enguidanos S, Jamison P, et al. Increased satisfaction with care and lower costs: results of a randomized trial of in-home palliative care. J Am Geriatr Soc 2007;55:993-1000.

5 Hui D, Kim SH, Roquemore J, et al. Impact of timing and setting of palliative care referral on quality of end-of-life care in cancer patients. Cancer 2014;120:1743-9.

6 Hughes-Hallett T, Craft A, Davies C, et al. Funding the Right Care and Support for Everyone: Creating a fair and transparent funding system; the final report of the Palliative Care Funding Review. 2011. Retrived January 2015. https://wwwgovuk/ government/uploads/system/uploads/attachment_data/file/215107/dh_133105pdf

7 World Health Organization. Palliative care: the solid facts. Geneva: World Health Organization, 2004.

8 Quill TE, Abernethy AP. Generalist plus specialist palliative care — creating a more sustainable model. NEngl J Med 2013;368:1173-5.

9 General Medical Council. Tomorrow's doctors: outcomes and standards for undergraduate medical education. Manchester: General Medical Council, 2009. ISBN: 978-0-901458-36-0.

10 Royal College of Nursing. Defining nursing. London: Royal College of Nursing, 2014. https://www.rcn.org.uk/professional-development/publications/pub-004768

11 Francis R. Report of the Mid Staffordshire NHS Foundation Trust Public Inquiry: executive summary. London: The Stationery Office. HC 947, 2013.

12 Neuberger J, Gutherie C, Aaronovitch D, et al. More care, less pathway — a review of the Liverpool Care Pathway. Department of Health, 2013.

13 Leung JM, Udris EM, Uman J, et al. The effect of end-of-life discussions on perceived quality of care and health status among patients with COPD. Chest 2012;142:128-33.

14 Wright AA, Zhang B, Ray A, et al. Associations between end-of-life discussions, patient mental health, medical care near death, and caregiver bereavement adjustment. JAMA 2008;300:1665-73

15 Davison SN. End-of-life care preferences and needs: perceptions of patients with chronic kidney disease. Clin J Am Soc Nephrol 2010;5:195-204.

16 You JJ, Dodek P, Lamontagne F, et al. What really matters in end-of-life discussions? Perspectives of patients in hospital with serious illness and their families. CMAJ 2014;186:E679-87.

17 Mack JW, Cronin A, Keating NL, et al. Associations between end-of-life discussion characteristics and care received near death: a prospective cohort study. I Clin Oncol 2012:30:4387-95.

18 Brinkman-Stoppelenburg A, Rietjens JA, van der Heide A. The effects of advance care planning on end-of-life care: a systematic review. Palliat Med 2014; 28:1000-25.

19 You JJ, Downar J, Fowler RA, et al. Barriers to goals of care discussions with seriously ill hospitalized patients and their families: a multicenter survey of clinicians. JAMA Intern Med 2015;175:549-56.

20 Zaros MC, Curtis JR, Silveira MJ, et al. Opportunity lost: end-of-life discussions in cancer patients who die in the hospital. J Hosp Med 2013;8:334-40.

21 Park EM, Check DK, Yopp JM, et al. An exploratory study of end-of-life prognostic communication needs as reported by widowed fathers due to cancer. Psychooncology 2015;24:1471-6.

22 Shirado A, Morita T, Akazawa T, et al. Both maintaining hope and preparing for death: effects of physicians' and nurses' behaviors from bereaved family members' perspectives. J Pain Symptom Manage 2013;45:848-58.

23 Clayton JM, Hancock KM, Butow PN, et al. Clinical practice guidelines for communicating prognosis and end-of-life issues with adults in the advanced stages of a life-limiting illness, and their caregivers. Med J Aust 2007;186(12 Suppl):S77, s9, s83-108.

24 Clayton JM, Butow PN, Tattersall MH. When and how to initiate discussion about prognosis and end-of-life issues with terminally ill patients. J Pain Symptom Manage 2005;30:132-44

25 Almack K, Cox K, Moghaddam N, et al. After you: conversations between patients and healthcare professionals in planning for end of life care. BMC Palliat Care 2012:11:15.

26 Hancock K, Clayton JM, Parker SM, et al. Truth-telling in discussing prognosis in advanced life-limiting illnesses: a systematic review. Palliat Med 2007;21:507-17.

27 De Vleminck A, Pardon K, Beernaert K, et al. Barriers to advance care planning in cancer, heart failure and dementia patients: a focus group study on general practitioners' views and experiences. PLOS ONE 2014;9:e84905.

28 Hancock K, Clayton JM, Parker SM, et al. Discrepant perceptions about end-of-life communication: a systematic review. J Pain Symptom Manage 2007:34:190-200.

29 Momen NC, Barclay SI. Addressing 'the elephant on the table': barriers to end of life care conversations in heart failure-a literature review and narrative synthesis. Curr Opin Support Palliat Care 2011;5:312-16. 
30 Pfeil TA, Laryionava K, Reiter-Theil S, et al. What keeps oncologists from addressing palliative care early on with incurable cancer patients? An active stance seems key. Oncologist 2015;20:56-61.

31 Lovell A, Yates P. Advance Care Planning in palliative care: a systematic literature review of the contextual factors influencing its uptake 2008-2012. Palliat Med 2014;28:1026-35.

32 Houben $\mathrm{CH}$, Spruit MA, Schols JM, et al. Patient-clinician communication about end-of-life care in patients with advanced chronic organ failure during one year. J Pain Symptom Manage 2015;49:1109-15.

33 Kendall M, Carduff E, Lloyd A, et al. Different experiences and goals in different advanced diseases: comparing serial interviews with patients with cancer, organ failure, or frailty and their family and professional carers. J Pain Symptom Manage 2015;50:216-24.

34 Clayton JM, Hancock K, Parker S, et al. Sustaining hope when communicating with terminally ill patients and their families: a systematic review. Psychooncology 2008;17:641-59.

35 Abdul-Razzak A, You J, Sherifali D, et al. 'Conditional candour' and 'knowing me': an interpretive description study on patient preferences for physician behaviours during end-of-life communication. BMJ Open 2014;4:e005653.

36 Emanuel EJ, Fairclough DL, Wolfe $\mathrm{P}$, et al. Talking with terminally ill patients and their caregivers about death, dying, and bereavement: is it stressful? Is it helpful? Arch Intern Med 2004;164:1999-2004.

37 Friedrichsen $\mathrm{M}$, Lindholm A, Milberg A. Experiences of truth disclosure in terminally ill cancer patients in palliative home care. Palliat Support Care 2011;9:173-80.

38 Parker SM, Clayton JM, Hancock K, et al. A systematic review of prognosticl end-of-life communication with adults in the advanced stages of a life-limiting illness: patient/caregiver preferences for the content, style, and timing of information. J Pain Symptom Manage 2007;34:81-93.

39 Hudak P, Frankel R, Braddock C, et al. Do patients' communication behaviors provide insight into their preferences for participation in decision making? Med Decis Making 2008;28:385-93.

40 Garfield S, Smith F, Francis SA, et al. Can patients' preferences for involvement in decision-making regarding the use of medicines be predicted? Patient Educ Couns 2007:66:361-7.

41 Murtagh FE, Thorns A. Evaluation and ethical review of a tool to explore patient preferences for information and involvement in decision making. J Med Ethics 2006:32:311-15.

42 Pollak Kl, Jones J, Lum HD, et al. Patient and caregiver opinions of motivational interviewing techniques in role-played palliative care conversations: a pilot study. J Pain Symptom Manage 2015;50:91-8.

43 Aslakson RA, Wyskiel R, Thornton I, et al. Nurse-perceived barriers to effective communication regarding prognosis and optimal end-of-life care for surgical ICU patients: a qualitative exploration. J Palliat Med 2012;15:910-15.

44 Granek L, Krzyzanowska MK, Tozer R, et al. Oncologists' strategies and barriers to effective communication about the end of life. J Oncol Pract 2013;9:e129-35.

45 Murray $C D$, McDonald $C$, Atkin $\mathrm{H}$. The communication experiences of patients with palliative care needs: a systematic review and meta-synthesis of qualitative findings. Palliat Support Care 2015;13:369-83.

46 Thorne S, Armstrong EA, Harris SR, et al. Patient real-time and 12-month retrospective perceptions of difficult communications in the cancer diagnostic period. Qual Health Res 2009;19:1383-94.

47 Karlsson M, Milberg A, eds. Abstract FC14.2: pushing up daises, slipping away or dying - a qualitative study on the expressions of death and dying among family members of palliative patients. 14th World Congress of the European Association for Palliative Care; Copenhagen, Denmark, 2015.

48 Griffiths J, Wilson C, Ewing G, et al. Improving communication with palliative care cancer patients at home-a pilot study of SAGE \& THYME communication skills model. Eur J Oncol Nurs 2015;19:465-72.

49 Connolly M, Perryman J, McKenna Y, et al. SAGE \& THYME: a model for training health and social care professionals in patient-focussed support. Patient Educ Couns 2010;79:87-93.

50 Clayton JM, Butow PN, Waters A, et al. Evaluation of a novel individualised communication-skills training intervention to improve doctors' confidence and skills in end-of-life communication. Palliat Med 2013;27:236-43.

51 Grossman S. Development of the palliative care of dying critically III patients algorithm: implications for critical care nurses. J Hosp Palliat Nurs 2013;15:355-9.

52 Head BA, Schapmire T, Earnshaw L, et al. Evaluation of an interdisciplinary curriculum teaching team-based palliative care integration in oncology. J Canc Educ 2016;31:358-65.
53 Yang HB, Nelesen RA, Montross LP, et al. Comparison of international medical graduates with US medical students and residents after a four-week course in palliative medicine: a pilot study. J Palliat Med 2013;16:471-7.

54 Simon J, Porterfield P, Bouchal SR, et al. 'Not yet' and 'Just ask': barriers and facilitators to advance care planning — a qualitative descriptive study of the perspectives of seriously ill, older patients and their families. BMJ Support Palliat Care 2015;5:54-62.

55 Walczak A, Butow PN, Clayton JM, et al. Discussing prognosis and end-of-life care in the final year of life: a randomised controlled trial of a nurse-led communication support programme for patients and caregivers. BMJ Open 2014;4:e005745.

56 Allen SL, Davis KS, Rousseau PC, et al. Advanced care directives: overcoming the obstacles. J Grad Med Educ 2015;7:91-4.

57 Clayton JM, Butow PN, Tattersall MHN, et al. Randomized controlled trial of a prompt list to help advanced cancer patients and their caregivers to ask questions about prognosis and end-of-life care. J Clin Oncol 2007;25:715-23.

58 Walczak A, Butow PN, Bu S, et al. A systematic review of evidence for end-of-life communication interventions: who do they target, how are they structured and do they work? Patient Educ Couns 2016;99:3-16.

59 Claxton R, Marks S, Buranosky R, et al. The educational impact of weekly e-mailed fast facts and concepts. J Palliat Med 2011;14:475-81.

60 Pelayo M, Cebrián D, Areosa A, et al. Effects of online palliative care training on knowledge, attitude and satisfaction of primary care physicians. BMC Fam Pract 2011;12:37.

61 Fujimori $M$, Shirai $Y$, Asai $M$, et al. Effect of communication skills training program for oncologists based on patient preferences for communication when receiving bad news: a randomized controlled trial. J Clin Oncol 2014;32:2166-72.

62 Szmuilowicz E, el-Jawahri A, Chiappetta L, et al. Improving residents' end-of-life communication skills with a short retreat: a randomized controlled trial. J Palliat Med 2010;13:439-52.

63 Delvaux N, Razavi D, Marchal S, et al. Effects of a 105 hours psychological training program on attitudes, communication skills and occupational stress in oncology: a randomised study. Br J Cancer 2004;90:106-14.

64 Lienard A, Merckaert I, Libert Y, et al. Transfer of communication skills to the workplace during clinical rounds: impact of a program for residents. PLOS ONE 2010;5:e12426.

65 Tulsky JA, Arnold RM, Alexander SC, et al. Enhancing communication between oncologists and patients with a computer-based training program: a randomized trial. Ann Intern Med 2011;155:593-601.

66 Houben $\mathrm{CH}$, Spruit MA, Groenen MT, et al. Efficacy of advance care planning: a systematic review and meta-analysis. J Am Med Dir Assoc 2014;15:477-89.

67 Curtis JR, Back AL, Ford DW, et al. Effect of communication skills training for residents and nurse practitioners on quality of communication with patients with serious illness: a randomized trial. JAMA 2013;310:2271-81.

68 Johnson LA, Gorman C, Morse R, et al. Does communication skills training make a difference to patients' experiences of consultations in oncology and palliative care services? Eur J Cancer Care (Engl) 2013;22:202-9.

69 Devilliers H, Amoura Z, Besancenot J-F, et al. Responsiveness of the 36-item Short Form Health Survey and the Lupus Quality of Life questionnaire in SLE. Rheumatology 2015;54:940-9.

70 Hulsman RL, Ros WJ, Winnubst JA, et al. The effectiveness of a computer-assisted instruction programme on communication skills of medical specialists in oncology. Med Educ 2002:36:125-34.

71 O'Connor M, Payne S. Discourse analysis: examining the potential for research in palliative care. Palliat Med 2006;20:829-34.

72 Andreassen P, Neergaard MA, Brogaard T, et al. Talking about sensitive topics during the advance care planning discussion: a peek into the black box. Palliat Support Care 2015;13:1669-76.

73 Murtagh FE, Addington-Hall JM, Higginson IJ. The value of cognitive interviewing techniques in palliative care research. Palliat Med 2007;21:87-93.

\section{Answers}

1. (T); 2. (F); 3. (F); 4. (T); 5. (T) 